Article

\title{
Extraction of Humic Acid from Lignite by KOH-Hydrothermal Method
}

\author{
Gan Cheng ${ }^{1,2, *}$, Zeyu Niu ${ }^{3}$, Chuanxiang Zhang ${ }^{1,2, *}$, Xiaoming Zhang ${ }^{1}$ and Xusheng $\mathrm{Li}^{4}$ \\ 1 College of Chemistry and Chemical Engineering, Henan Polytechnic University, Jiaozuo 454000, China; \\ zxmflys@126.com \\ 2 Henan Key Laboratory of Coal Green Transformation, Henan Polytechnic University, Jiaozuo 454000, China \\ 3 College of Food Science and Engineering, Central South University of Forestry and Technology, \\ Changsha 410004, China; penny970720@163.com \\ 4 School of Chemical Engineering \& Technology, China University of Mining and Technology, \\ Xuzhou 221116, China; lxswhy@126.com \\ * Correspondence: chenggan464@126.com (G.C.); zcx223@hpu.edu.cn (C.Z.); Tel.: +86-3913-986-812 (G.C.)
}

Received: 8 March 2019; Accepted: 26 March 2019; Published: 31 March 2019

check for updates

\begin{abstract}
Humic acid (HA) was extracted by a hydrothermal method from Huolinhe lignite from Inner Mongolia. The effects of the alkali-to-carbon mass ratio, water-to-coal mass ratio, reaction temperature, and reaction time on the HA yield were investigated. The physicochemical characterization of the products was performed, and the reaction mechanism was explored. Raw coal, HA, and residual coal were characterized using Fourier-transform infrared spectroscopy (FTIR), ultraviolet-visible spectroscopy (UV-VIS), elemental composition, and X-ray diffraction (XRD) analyses and compared to each other. The maximum HA yield (90.2\%) was obtained from the $0.250-0.180 \mathrm{~mm}$ size fraction of the coal sample at a reaction temperature and time of $190{ }^{\circ} \mathrm{C}$ and $7 \mathrm{~h}$. Proximate analysis proved that the ash and sulfur of lignite can be removed by hydrothermal treatment. Elemental analysis showed that the $\mathrm{O} / \mathrm{C}$ and $\mathrm{H} / \mathrm{C}$ ratios were highest for HA, followed by those for residual coal and raw coal, indicating an increase in the oxygen and hydrogen content of HA. FTIR and UV-VIS analyses showed that hydrothermal extraction destroyed the macromolecular structure of lignite. Moreover, the organics were degraded and hydrolyzed during the reaction process.
\end{abstract}

Keywords: humic acid; hydrothermal; lignite; XRD; FTIR

\section{Introduction}

Humic acid (HA) is a complex mixture in which there can be small, large, and polydisperse molecules formed and accumulated through the decomposition and transformation of microorganisms and a series of geochemical reactions [1,2]. Schulten and Schnitzer [3] proposed a structure for HA formed by alkyl benzene moieties attached through covalent bonds. Piccolo [4] proposed that it is a self-assembled superstructure with relatively small heterogeneous molecules held together primarily by hydrophobic dispersive forces and hydrogen bonds. Many authors thought that HA had no precise structures, which depend on the source that generated them and the specific extraction conditions [5].

HA contains a high number of active groups such as carboxyl groups, phenolic hydroxyl groups, carbonyl groups, sulfonic acid groups, and methoxy groups, which have a crucial influence on the acidity, ion exchange properties, colloidal properties, and complexation properties [6]. HA is widely used in agriculture, medicine, health, wastewater treatment $[7,8]$, and other applications. The existence of carboxylic and phenolic groups results in HA carrying a predominantly negative charge in aqueous solutions under normal environmental conditions $[9,10]$. Humic acid can efficiently purify metal ions 
and improve water quality [11,12]. In addition, HA can also be used as surfactants, flocculants, ceramic additives, battery cathode expansion agent, boiler anticrustator, water-soluble fertilizer, compound fertilizer, soil remediation agent, etc. $[13,14]$. High functionality of the surface ensures that HA is a good adsorbent with an excellent capacity for treating the pollution caused by waste gases $[15,16]$.

HA widely exists in lakes, marsh, soils [17], peat, lignite, oxidized bituminous coal, weathered coal, shale, and flora/fauna residues [18-20]. Lignite has attracted considerable attention, as its reserves account for nearly $45 \%$ of global coal reserves [21-23]. However, its abundant oxygen functional moieties, low calorific value, and high moisture content have critically restricted its direct and wide use [24-27]. Compared to HAs originating from soil and peat, lignite HAs are characterized by higher carbon content and biochemical activity, lower oxygen and nitrogen content, more aromatic moieties, and fewer carboxylic groups. Lignite HA is characterized by the presence of methylene and ethylene bridges between the aromatic rings. In contrast to soil humic acids, lignite humic acids were shown to contain saturated long chain alkanoic acids with a strong predominance of even numbered homologues [28].

Humic acids are insoluble under acidic conditions, but become soluble and extractable in alkaline solutions. Multiple approaches can be used to extract HA from lignite, including physical, chemical (alkaline [29] and acid), and biological methods [30]. Stefanova et al. [31] extracted HA from Bulgarian lignite using a $\mathrm{NaOH}$ dissolution and $\mathrm{HCl}$ precipitation, obtaining 83\% $\mathrm{HA}$ content. Cihlář et al. [32] first dissolved South Moravian lignite with a $\mathrm{NaOH}(0.5 \mathrm{~mol} / \mathrm{L})$ and $\mathrm{Na}_{4} \mathrm{P}_{2} \mathrm{O}_{7}(0.1 \mathrm{~mol} / \mathrm{L})$ solution, followed by pickling with a $0.5 \% \mathrm{HCl}-\mathrm{HF}$ solution, and $\mathrm{HA}$ was finally obtained by $\mathrm{H}_{2} \mathrm{O}_{2} / \mathrm{HNO}_{3}$ oxidation treatment. Drosos et al. [33] prepared a water-soluble humic acid-like polycondensate (HALP) that mimicked the fundamental physicochemical and spectroscopic properties of natural HA. The polymerization procedures were as follows; a gallic acid and protocatechuic acid (mass ratio is 1:1) suspension liquid ( $0.5 \mathrm{~L}$ ) was adjusted to $\mathrm{pH} 1$ using $\mathrm{HCl}$ and continuously stirred for $12 \mathrm{~h}$ at $25^{\circ} \mathrm{C}$ in a closed glass jar, and the $\mathrm{pH}$ was then adjusted to 10.5 with $\mathrm{NaOH}$. Khemakhem et al. [34] isolated a water-soluble HA and melanin-like polymer complex from olive mill waste waters (OMWW) by using ammonium sulphate as a natural additive.

Compared to the above methods, the hydrothermal method [35] is an effective approach for obtaining higher HA yields. Hydrothermal extraction is based on the theory that subcritical water can dissolve organic matter. The reaction is carried out in a special closed container with hot-compressed water above $100{ }^{\circ} \mathrm{C}$ [36], and undissolvable/insoluble substances are dissolved in aqueous medium [37]. Elemental analysis and spectroscopic methods including UV-VIS and FTIR spectroscopy are usually used for the characterization of HAs. Huang et al. [38] examined the effects of water content and particle size on the yield and reactivity of lignite char. A thermogravimetric analyzer (TGA) was used for measuring the reactivity of the chars after pyrolysis and gasification. For the $<75 \mu \mathrm{m}$ coal particles, the high water content decreased the char yield; for the $0.9-2.0 \mathrm{~mm}$ coal particles, the high water content contributed to the increase in char yield. Liu et al. [39] studied the structural changes in lignite during hydrothermal treatment. The weak bonds in lignite were broken, and the oxygen functional groups decreased gradually during hydrothermal treatment below $240{ }^{\circ} \mathrm{C}$. The covalent bonds began to break above $240^{\circ} \mathrm{C}$. Liu et al. [40] and Chang et al. [41] modified lignite by the hydrothermal method. The carboxyl and carbonyl content decreased significantly with an increase in the temperature after hydrothermal treatment. Wang et al. [42] studied the effects of hydrothermal treatment on the swelling, extraction, and liquefaction performances of Shenhua coal. The results showed that hydrothermal treatment could hydrogenate, deash, and devolatilize lignite. The IR spectra showed that the forms of noncovalent bonds (hydrogen bonds) were changed by hydrothermal treatment, the weak covalent bonds (e.g., ether bonds and ester bonds) hydrolyzed, and the side-chains of the aromatic rings broke. The hydrothermal temperature had a strong influence on the reaction process. Zhang et al. [43] extracted fulvic acid from weathered coal using hydrothermal catalytic oxidation with nano-copper oxide as the catalyst and hydrogen peroxide as a green oxidant. The maximum total HA and fulvic 
acid contents were $73.23 \%$ and $8.98 \%$, respectively. HA could be broken up into two soluble and two insoluble fractions by successive dissolution in deionized water at near-neutral $\mathrm{pH}$ [44].

The above analyses showed that hydrothermal pretreatment destroys the macromolecular structure of lignite and increases the content of oxygen-containing functional groups. In the present study, $\mathrm{KOH}$ solution was adopted to extract $\mathrm{HA}$ from lignite. The reaction equation is given by

$$
\mathrm{R}-(\mathrm{COOH})_{\mathrm{n}}+\mathrm{nKOH} \rightarrow \mathrm{R}-(\mathrm{COOK})_{\mathrm{n}}+\mathrm{nH}_{2} \mathrm{O}
$$

In this study, the extraction process of HA from lignite was optimized by evaluating the effects of different factors, i.e., alkali-to-carbon mass ratio, reaction time, reaction temperature, water-to-coal mass ratio, and coal size. Characterization of the extracted humic acid was also done to further evaluate its composition and structure through proximate analysis by UV-VIS, FTIR, XRD, etc. This study will further the economic value and application of lignite [45].

\section{Materials and Methods}

\subsection{Materials}

Chemicals of analytical reagent grade or better as well as deionized water were used in the experiments. Hydrochloric acid and potassium hydroxide were purchased from Yantai Shuangshuang Chemical Industry Co. Ltd. and Tianjin Dalu Chemical Reagent Factory, respectively. Lignite was collected from Huolinhe in Inner Mongolia, China. After crushing and screening, the raw coal was divided into five size fractions, namely, $2-0.850 \mathrm{~mm}, 0.850-0.425 \mathrm{~mm}, 0.425-0.250 \mathrm{~mm}, 0.250-0.180 \mathrm{~mm}$, and $0.180-0.150 \mathrm{~mm}$. Finally, the prepared coal samples were tightly sealed.

\subsection{Experimental Setup and Procedures}

Hydrothermal tests were performed in a stainless steel reactor [46]. The detailed process is shown in Figure 1. The alkali-to-carbon mass ratio (mass ratio of potassium hydroxide to coal sample), water-to-coal mass ratio (mass ratio of water-to-coal sample), reaction time ( $3-11 \mathrm{~h}$ ), and reaction temperature $\left(130-190^{\circ} \mathrm{C}\right)$ were studied to determine their effects on the HA yield.

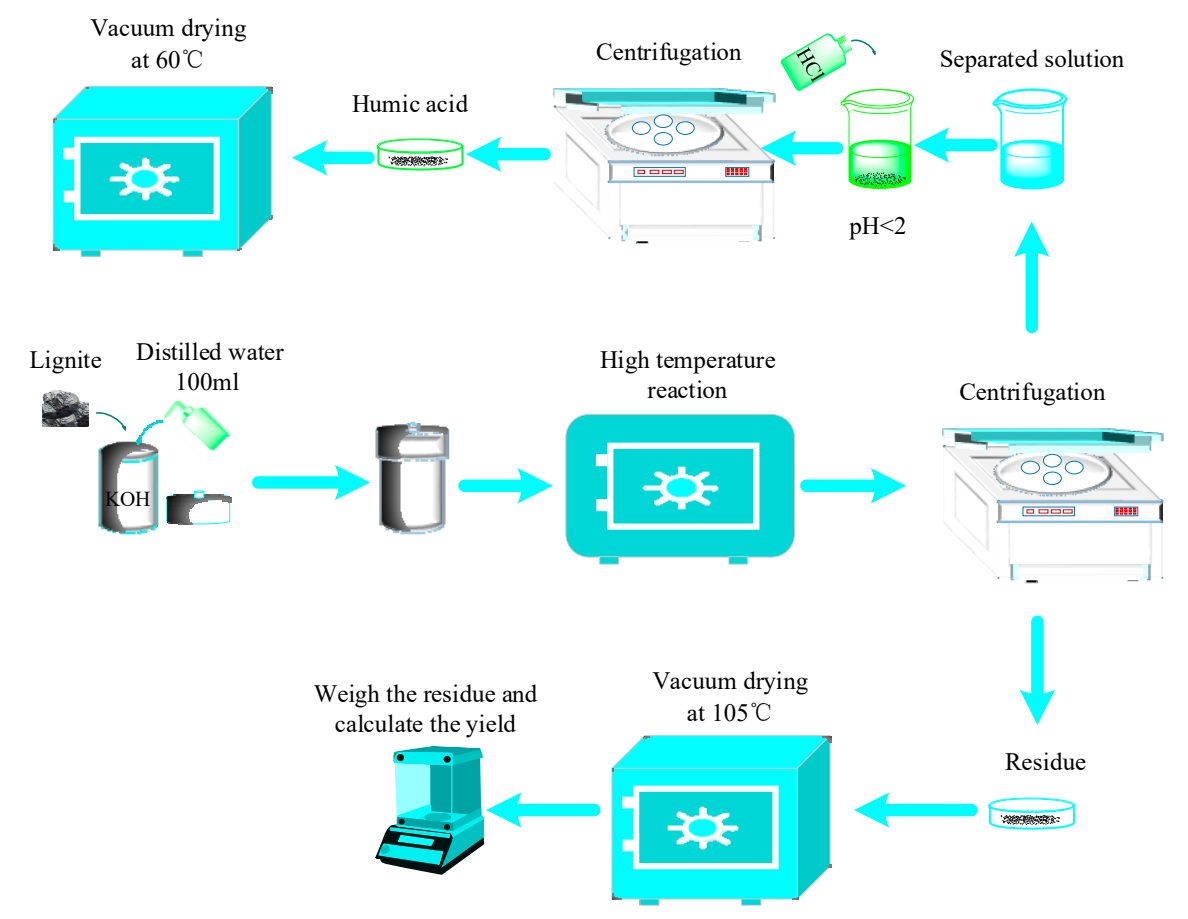

Figure 1. Flow chart of humic acid (HA) extracted by the hydrothermal method. 
The process was as follows.

Step 1: Coal samples were dried in a vacuum oven at $105^{\circ} \mathrm{C}$ to constant weight [47]. An air-dried sample $(20 \mathrm{~g})$ was treated with potassium hydroxide $(\mathrm{KOH})$ and deionized water in the reactor. Then, the reactor was placed into oven $\left(130-190^{\circ} \mathrm{C}\right)$. After the reaction was finished, the kettle was naturally cooled to room temperature [48].

Step 2: The supernatant was separated from residues by centrifugation. After centrifugation, the residuals were washed with distilled water until almost reaching neutral $\mathrm{pH}$. Then, the residuals were filtered and dried in a vacuum oven at $105^{\circ} \mathrm{C}$.

Step 3: The supernatant and cleansing solution were acidized to $\mathrm{pH}<2$ with $\mathrm{HCl}$, further separated by centrifugation, and dried in a vacuum oven at $60{ }^{\circ} \mathrm{C}$. The obtained dried materials were HA.

The HA yield was calculated on an air-dried basis according to the following formula.

$$
\varepsilon=\frac{\mathrm{M}_{Y M}\left(1-M_{\mathrm{ad}}\right)-M_{C Y}}{\mathrm{M}_{Y M}\left(1-M_{\mathrm{ad}}\right)}
$$

where $\varepsilon$ is the yield of $\mathrm{HA}, \% ; M_{\mathrm{YM}}$ is the mass of lignite, $\mathrm{g} ; M_{\mathrm{CY}}$ is the mass of the residual coal, $\mathrm{g}$; and $M_{\mathrm{ad}}$ is the water content in raw coal, $\%$.

According to the GB/T212-2008 standard [49], the moisture content $\left(M_{a d}\right)$, ash content $\left(A_{d}\right)$, volatile content $\left(\mathrm{V}_{\mathrm{daf}}\right)$, and fixed carbon content $\left(\mathrm{FC}_{\mathrm{daf}}\right)$ were detected based on the air-dried samples. The elements $\mathrm{C}, \mathrm{H}, \mathrm{O}, \mathrm{N}$, and $\mathrm{S}$ were analyzed based on the air-dried samples by a TE-CHN700B Elemental Analyzer (Thermo Fisher Scientific, USA) in accordance with the GB/T476-2001 standard. The total HA content in raw coal was determined by the GB/T11957-2001 volumetric method, and the HA content of raw coal was $14.6 \%$.

\section{Results}

\subsection{Effect of Alkali-to-Carbon Mass Ratio}

The effect of the alkali-to-carbon mass ratio (0.3:1-1.5:1) on the HA yield was analyzed for a hydrothermal temperature of $190^{\circ} \mathrm{C}$, water-to-coal mass ratio of 1:20, reaction time of $7 \mathrm{~h}$, and coal sample size of $0.250-0.180 \mathrm{~mm}$. The results are shown in Figure 2.

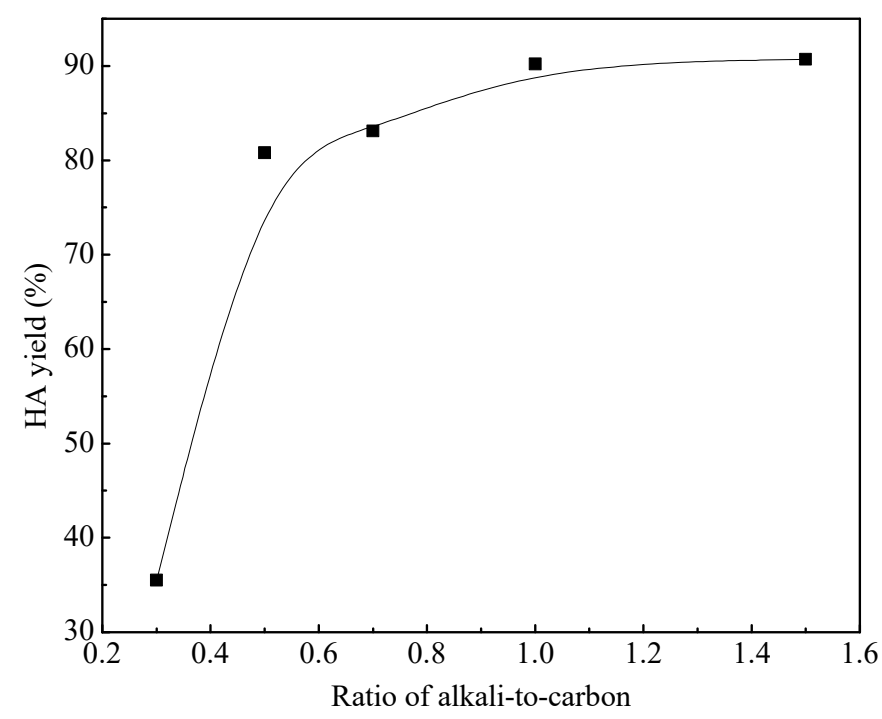

Figure 2. Effect of the alkali-to-carbon mass ratio on the HA yield.

As shown in Figure 2, as the alkali-to-carbon mass ratio increased, the HA yield increased rapidly from $35.5 \%$ to $80.8 \%$, and then remained stable at $90.7 \%$. The HA in raw coal forms a structurally stable 
chelate complex with metal ions such as calcium, magnesium, and aluminum. The HA content in the raw coal was low, and the addition of $\mathrm{KOH}$ destroyed the chelating forces between $\mathrm{HA}$ and metal ions. Therefore, the HA was easier to dissociate from the coal. In addition, the increase in the $\mathrm{OH}^{-}$ concentration made HA more available for reaction (1) [50]. Because the amount of metal ions in the coal sample was fixed, the HA yield no longer increased even though the amount of $\mathrm{KOH}$ increased continuously. When the alkali-to-carbon mass ratio was 1.5, the HA yield reached a maximum of $90.7 \%$, but the increase was not significant. Thus, 1:1 was selected as the optimal alkali-to-carbon mass ratio for HA extraction.

\subsection{Effects of Reaction Time and Temperature}

The effect of the reaction time on HA yield was further investigated after the optimal alkali-to-carbon mass ratio was determined. As shown in Figure 3, the HA yield increased from $54.4 \%$ to $90.2 \%$ as the reaction time varied from 3 to $7 \mathrm{~h}$. At reaction times exceeding $7 \mathrm{~h}$, the HA yield decreased from $90.2 \%$ to $84.7 \%$. A short time resulted in an inadequate reaction, and HA easily decomposed at high temperatures and pressures. Therefore, $7 \mathrm{~h}$ was selected as the optimal time.

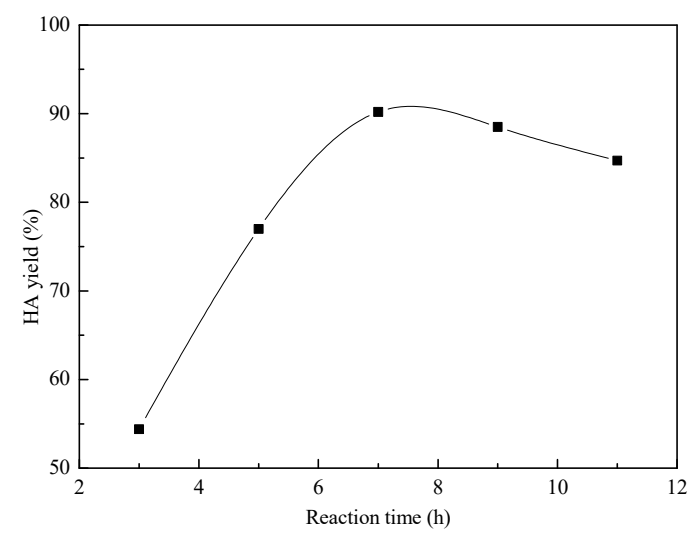

Figure 3. Effect of the reaction time on the HA yield.

After determining the optimal reaction time, the effect of the temperature $\left(130-190{ }^{\circ} \mathrm{C}\right)$ was investigated (Figure 4). The HA yield increased sharply from $20 \%$ to $90.2 \%$ as the temperature increased from 130 to $190^{\circ} \mathrm{C}$ and then increased slowly until the temperature rose to $210^{\circ} \mathrm{C}$. Most of the intermolecular forces in coal are physical associations and are weak. A high temperature resulted in the destruction of the molecular structures, thereby releasing HA in the lignite. However, high temperatures also led to the breaking of noncovalent bonds (e.g., hydrogen bonds), the hydrolysis of weak covalent bonds (e.g., ether bonds and ester bonds), and the cleavage of side-chain bonds (e.g., aromatic rings and fat bonds). With increasing hydrothermal temperature, the permittivity and polarity of the water in the reactor decreased, the dissolving capacity of the intermediate polar and nonpolar organic compounds in the lignite was enhanced, and the amount of HA dissolved in lye increased. When the temperature was greater than $210{ }^{\circ} \mathrm{C}$, the increase in the HA yield was not very obvious. A higher temperature corresponds to greater energy consumption and economic costs. Therefore, $190^{\circ} \mathrm{C}$ was selected as the optimal reaction temperature. 


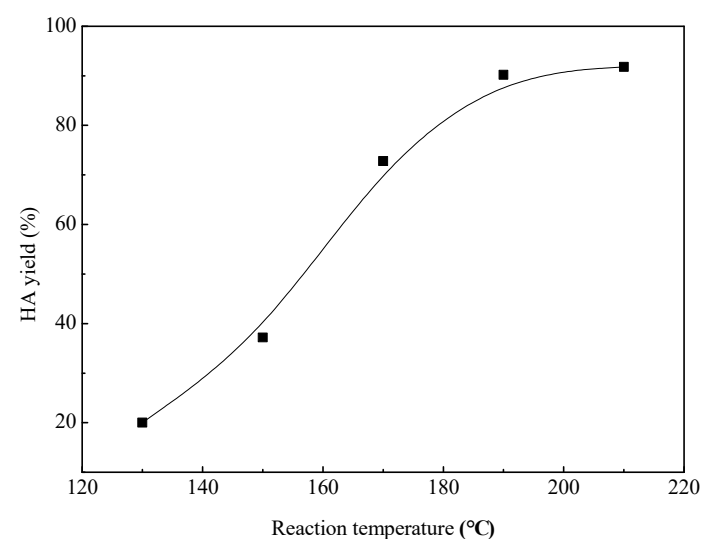

Figure 4. Effect of the reaction temperature on the HA yield.

\subsection{Effects of the Water-to-Coal Mass Ratio and Coal Size}

The effect of the water-to-coal mass ratio (ranging from 5:1 to 25:1) was then investigated. As shown in Figure 5, an increase in HA yield was observed as the water-to-coal mass ratio increased. When the water-to-coal mass ratio increased from 20:1 to $25: 1$, the HA yield increased from $90.2 \%$ to $91.2 \%$. The increase in HA yield was not obvious. Therefore, 20:1 was considered the optimal water-to-coal mass ratio.

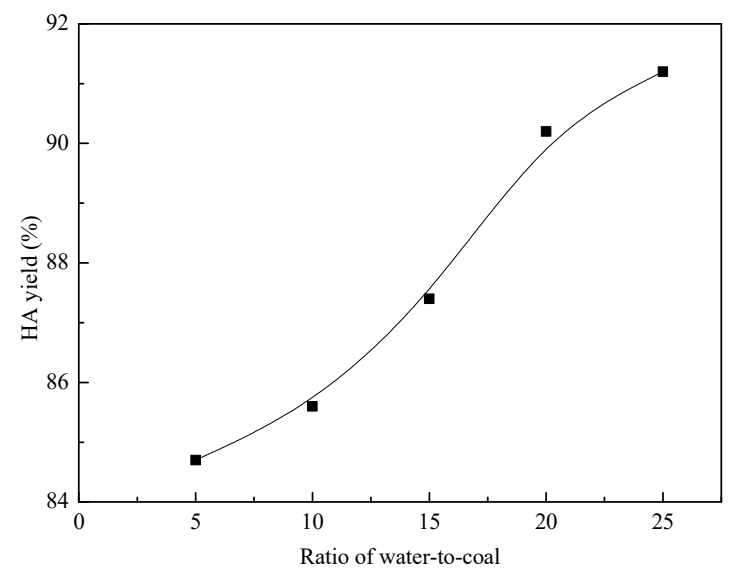

Figure 5. Effect of the water-to-coal mass ratio on the HA yield.

The effect of different coal sizes on the HA yield is shown in Figure 6. When the coal sample size decreased from $2-0.850 \mathrm{~mm}$ to $0.850-0.425 \mathrm{~mm}$, the HA yield slowly increased from $78.53 \%$ to $79.13 \%$. The HA yield increased rapidly from $79.13 \%$ to $90.2 \%$ in the size range from $0.425-0.250 \mathrm{~mm}$ to $0.250-0.180 \mathrm{~mm}$ but did not increase thereafter. After the raw coal was ground, its specific surface area and pore structure increased [51], and the organic matter in the coal was mildly oxidized, leading to the breakage and deformation of weak chemical bonds and alkyl structure, the reduction of relative molecular mass, and an increase in the content of oxygen-containing functional groups [52]. Therefore, decreasing the coal sample size contributed not only to the contact between the $\mathrm{KOH}$ solution and the coal sample but also to the improvement in the HA yield. 


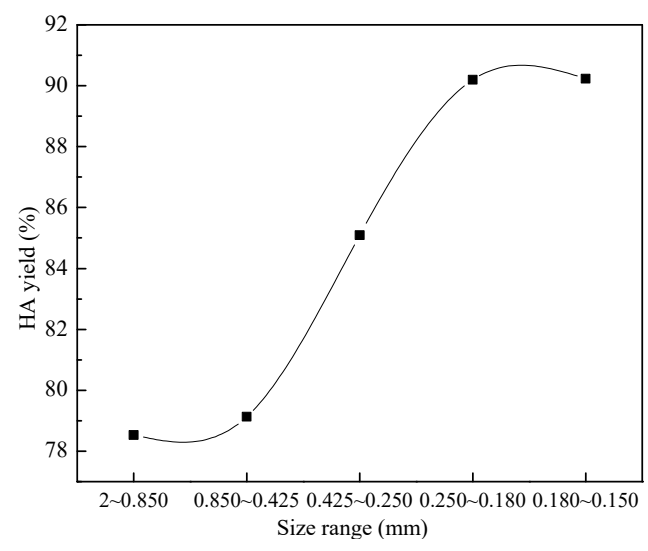

Figure 6. Effect of coal size on the HA yield.

The observations above indicated that a satisfactory yield of HA $(90.02 \%)$ was obtained from the $0.250-0.180 \mathrm{~mm}$ size fraction of the coal sample at a reaction temperature of $190{ }^{\circ} \mathrm{C}$, reaction time of $7 \mathrm{~h}$, alkali-to-carbon mass ratio of 1:1, and water-to-coal mass ratio of 20:1.

\subsection{Physicochemical Characterization and Mechanism Analyses}

The residual coal and HA obtained under the optimal conditions were characterized. Here, raw coal and residual coal are denoted by YM and CY, respectively. The proximate and ultimate analyses of raw lignite before and after the hydrothermal reaction are summarized in Table 1.

Table 1. Proximate and ultimate analyses of raw coal, residual coal, and HA.

\begin{tabular}{cccccccccccc}
\hline \multirow{2}{*}{ Products } & \multicolumn{4}{c}{ Proximate Analysis/\% } & \multicolumn{3}{c}{ Ultimate Analysis/\% } & \multicolumn{3}{c}{ Atomic Ratios } \\
\cline { 2 - 12 } & $\mathbf{M}_{\mathbf{a d}}$ & $\mathbf{A}_{\mathbf{d}}$ & $\mathbf{V}_{\mathbf{d a f}}$ & $\mathbf{F C}_{\mathbf{d a f}}$ & $\mathbf{N}_{\mathbf{d}}$ & $\mathbf{C}_{\mathbf{d}}$ & $\mathbf{H}_{\mathbf{d}}$ & $\mathbf{O}_{\mathbf{d}}$ & $\mathbf{O} / \mathbf{C}$ & $\mathbf{N} / \mathbf{C}$ & $\mathbf{H} / \mathbf{C}$ \\
\hline $\mathrm{YM}$ & 8.50 & 7.20 & 51.20 & 48.8 & 0.74 & 65.48 & 4.83 & 19.76 & 0.226 & 0.010 & 0.885 \\
$\mathrm{HA}$ & 0.96 & 4.92 & 40.09 & 59.91 & 1.68 & 55.44 & 6.02 & 21.28 & 0.288 & 0.026 & 1.303 \\
$\mathrm{CY}$ & 2.78 & 12.86 & 47.38 & 52.62 & 0.13 & 51.9 & 4.86 & 15.78 & 0.228 & 0.002 & 1.124 \\
\hline
\end{tabular}

As shown in Table 1, compared with YM, fixed carbon (FC) of HA increased, while the ash $\left(\mathrm{A}_{\mathrm{d}}\right)$, volatiles $\left(\mathrm{V}_{\mathrm{daf}}\right)$, and moisture $\left(\mathrm{M}_{\mathrm{ad}}\right)$ of HA decreased to different extents. These results proved that the hydrothermal treatment could deash and devolatilize lignite, and are in good agreement with previous reports in the literature. The content of the elements $\mathrm{N}, \mathrm{H}$, and $\mathrm{O}$ was higher in $\mathrm{HA}$ than in $\mathrm{YM}$ and $\mathrm{CY}$. The $\mathrm{O} / \mathrm{C}$ and $\mathrm{H} / \mathrm{C}$ atomic ratios were considered as an index for the measurement of aromaticity, with higher $\mathrm{O} / \mathrm{C}$ and $\mathrm{H} / \mathrm{C}$ atomic ratios corresponding to lower aromaticity [53]. Thus, the aromaticity of HA was lower than those of $\mathrm{YM}$ and $\mathrm{CY}$. The N/C atomic ratio reflected the amount of nitrogen in the organic material. The N/C ratio of HA was higher than that of $\mathrm{YM}$ and $\mathrm{CY}$ because nitrogen is mainly present in coal as organic pyridine or pyrrole [54]. The macromolecular structures of coal were destroyed, and the amount of oxygen-containing functional groups increased after the hydrothermal treatment.

The variations in the organic functional groups present in the YM, HA and CY samples were evaluated by FTIR analysis [55,56]. FTIR spectra were recorded in the range of $4500-400 \mathrm{~cm}^{-1}\left(2 \mathrm{~cm}^{-1}\right.$ resolution) using an infrared spectrometer (VERTEX 70, Germany). The results are shown in Figure 7. 


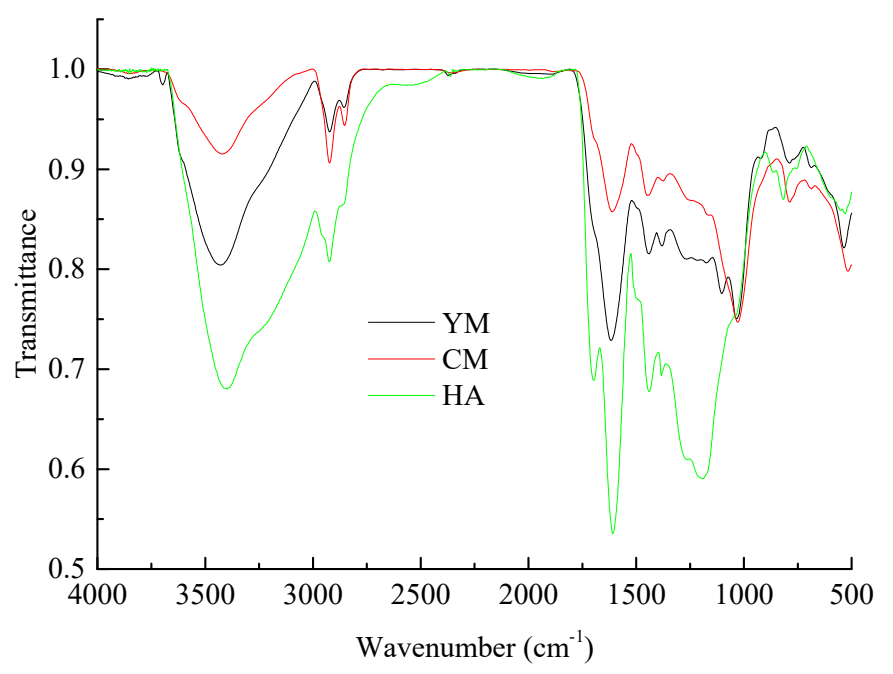

Figure 7. Fourier-transform infrared (FTIR) spectroscopy of YM, HA, and CY.

In the region of $\sim 3500 \mathrm{~cm}^{-1}$, the hydrogen bonding interactions from free hydroxyl groups and between the hydroxyl groups and $\pi$ bonds were weakened, indicating that hydrothermal treatment could change the hydrogen bond distribution of the raw coal [57]. In the 3600 to $3300 \mathrm{~cm}^{-1}$ range, the HA molecules had strong and broad absorption peaks. Because lignite contains almost no alcohols [58], these peaks should be attributed to the hydrogen bond-associated - $\mathrm{OH}$ stretching or -NH stretching vibration absorption peaks in phenolic and carboxylic acid structures [59]. This result showed that the hydrothermal reaction led to the hydrolysis of oxygen-containing functional groups such as ether bonds and ester bonds in raw coal and increased the content of carboxyl groups and phenolic hydroxyl groups in HA molecules. The stretching vibration absorption bands of aliphatic $\mathrm{C}-\mathrm{H}$ bonds were in the 3000 to $2700 \mathrm{~cm}^{-1}$ range. Among these wavenumbers, $2923 \mathrm{~cm}^{-1}$ and $2853 \mathrm{~cm}^{-1}$ were the symmetrical and asymmetric stretching vibrational peaks of the $\mathrm{C}-\mathrm{H}$ bonds in the saturated hydrocarbon groups $-\mathrm{CH}_{3}$ and $-\mathrm{CH}_{2}$, respectively. Within this range, the intensity of the absorption peak of $\mathrm{CH}_{3}$ at $2923 \mathrm{~cm}^{-1}$ was higher for HA than for the residual coal. However, the intensity of the $-\mathrm{CH}_{2}$ absorption peak at $2853 \mathrm{~cm}^{-1}$ was somewhat diminished, probably because the hydrothermal reaction broke the $\mathrm{CH}_{2}-\mathrm{CH}_{2}$ bond of the long-chain aliphatic macromolecular compounds in the raw coal and increased the $-\mathrm{CH}_{3}$ content. The peaks in the 1900 to $1000 \mathrm{~cm}^{-1}$ range were mainly attributed to the oxygen-containing functional groups in HA. The peak at $1696 \mathrm{~cm}^{-1}$ represented the sharp $\mathrm{C}=\mathrm{O}$ stretching vibration peak of carboxylic acids, aldehydes, and ketones. The peak at $1604 \mathrm{~cm}^{-1}$ may be attributed to $\mathrm{C}=\mathrm{O}$ in amides (amide I band), quinones, or ketones. The peaks in the broad frequency range of 1550 to $1790 \mathrm{~cm}^{-1}$ could be mainly attributed to protonated carboxylic acid $(-\mathrm{COOH})$, carboxylate anion (-COO-), and ester carbonyl (-COOR) groups, as well as to some other functional groups. The peak at $1440 \mathrm{~cm}^{-1}$ was assigned as the out-of-plane stretching vibrational absorption peak of $\mathrm{C}-\mathrm{H}$ in aliphatic $\mathrm{CH}_{3}$. The peak at $1371 \mathrm{~cm}^{-1}$ was attributed to the deformation of the hydroxyl group, the $\mathrm{C}-\mathrm{O}$ stretching vibration of a phenolic hydroxyl group, the $\mathrm{C}-\mathrm{H}$ deformation of a methyl or methylene group, or the asymmetric stretching vibration of $\mathrm{COO}-$. Aromatic structures had an absorption band within the range of 900 to $700 \mathrm{~cm}^{-1}$, which may be a deformation vibration of the aromatic ring out of the $\mathrm{CH}$ plane, indicating that the groups around the aromatic ring are substituted. HA showed significantly higher absorption band at $1040 \mathrm{~cm}^{-1}$ than $Y M$ and CY, indicating that HA had higher carbohydrate contents than YM and CY, since the absorption band at $1040 \mathrm{~cm}^{-1}$ was found to represent the $\mathrm{C}-\mathrm{O}$ asymmetric stretch vibration of carbohydrates. The element analytical result showed that $\mathrm{O} / \mathrm{C}$ ratios of $\mathrm{HA}$ was slightly higher than those of $\mathrm{YM}$ and $\mathrm{CY}$, this verified the conclusion that HA contain more carbohydrates than YM and CY [60]. The characteristic peaks at $1150 \mathrm{~cm}^{-1}$, representing asymmetric stretching of the $\mathrm{C}-\mathrm{O}-\mathrm{C}$ bridge. The peak observed at $1253 \mathrm{~cm}^{-1}$ can be assigned to the - $\mathrm{COO}$ (ester) group [61]. 
UV-VIS is an important method for detecting the molecular structure of HA. The location and intensity of the peaks are closely related to the unsaturated bonds and substituent groups of the molecule. UV-VIS (TU-1810SPC, Beijing Purkinje General Instrument Co., Ltd., China) analysis of the extracted HA solution was performed by recording the spectra from 200 to $900 \mathrm{~nm}$ and determining the absorbance variation of HA. Briefly, $20 \mathrm{mg}$ of dry HA sample was added to $70 \mathrm{~mL}$ of a $\mathrm{NaHCO}_{3}$ solution, and the $\mathrm{pH}$ was adjusted to 8.0 with $1 \% \mathrm{NaOH}$ solution or $0.1 \mathrm{~mol} / \mathrm{L} \mathrm{HCl}$ solution. Another sample without HA was used as the blank sample.

As shown in Figure 8, the absorption signal of HA decreased monotonically in the visible light region (400-700 nm). For the near-ultraviolet region (200-400 nm), there was a weak absorption plateau (aromatic structure) at approximately $300 \mathrm{~nm}$. A higher coal rank corresponds to deeper aromatization and a more pronounced absorption plateau [62]. It was inferred that the aromatized structure of the raw coal may have been destroyed by the hydrothermal reaction; there was a large absorption peak at $240 \mathrm{~nm}$, indicating the presence of conjugated carbonyl groups with two double bonds in the HA molecule. The absorption peaks at $240 \mathrm{~nm}$ represented the unsaturated thiol, aldehyde and hydrazine carbonyl groups [63]. This result was consistent with the results of the infrared spectrum analysis and indicated that HA contained more oxygen-containing functional groups than YM or CY.

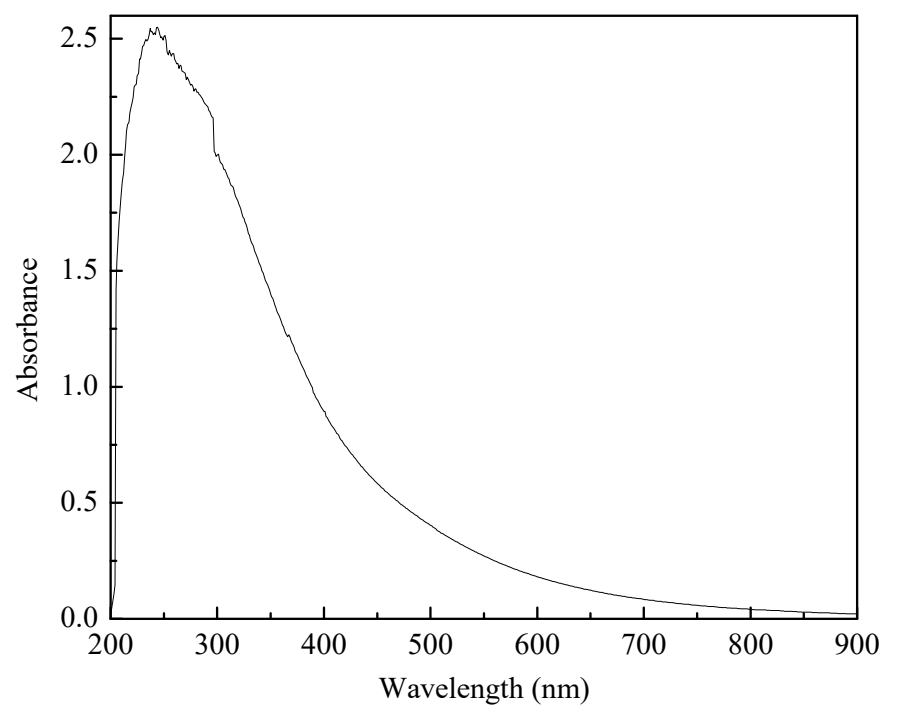

Figure 8. Ultraviolet-Visible (UV-VIS) spectra of HA.

The mineralogical compositions of YM, HA, and CY were determined by XRD, and the XRD patterns were recorded with an X-ray diffractometer (D/max-rA) over scanning angles $(2 \theta)$ with a step of $0.02^{\circ}$, as shown in Figure 9.

Figure 9 shows the XRD crystal phase analyses of YM, CY, and HA. The diffraction peaks at $20.85^{\circ}$, $26.65^{\circ}, 36.54^{\circ}, 39.45^{\circ}, 40.28^{\circ}, 42.46^{\circ}, 45.81^{\circ}, 50.14^{\circ}, 59.95^{\circ}$, and $68.32^{\circ}$ were the absorption peaks of $\mathrm{SiO}_{2}$ and the diffraction peaks at $12.37^{\circ}, 19.8^{\circ}, 20.36^{\circ}, 24.9^{\circ}$, and $34.99^{\circ}$ were kaolinite $\mathrm{Al}_{2} \mathrm{Si}_{2} \mathrm{O}_{5}(\mathrm{OH})_{4}$. Comparison of the crystal phases of $\mathrm{YM}, \mathrm{CY}$, and HA showed that there were many diffraction peaks in YM, but most of them had no obvious peak shape, which was related to the complex mineral structure of lignite. The qualitative analysis of the diffraction peak energy spectrum indicated that the inorganic elements existed mainly in the form of oxides or hydroxides. Almost no inorganic compound existed in HA. Compared to YM, the diffraction peaks of the $\mathrm{SiO}_{2}$ and kaolinite crystal planes in CY were very sharp. This difference was due to the destruction of chelation interactions between HA and metal elements after the hydrothermal treatment, which effectively reduced the metal element content. Furthermore, the addition of $\mathrm{HCl}$ during the acidification process also ionized the hydroxide precipitates produced by the reaction with $\mathrm{KOH}$, thereby reducing the inorganic element content in the HA. Therefore, the hydrothermal extraction of HA yielded a low-ash product than no treatment. 


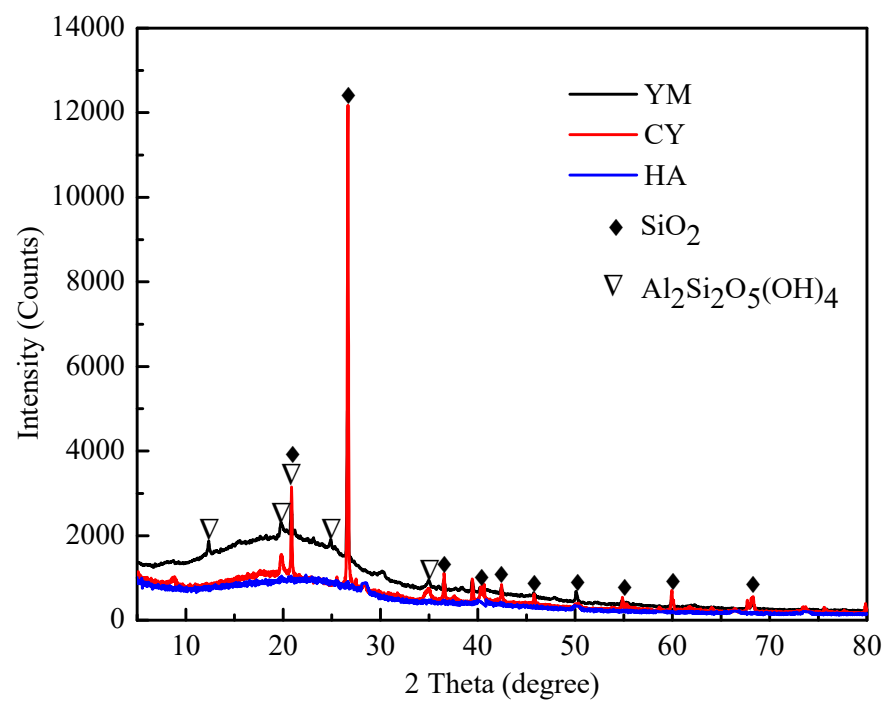

Figure 9. X-ray diffraction (XRD) patterns of the samples.

\section{Conclusions}

A KOH-hydrothermal method was used to extract HA from Inner Mongolia lignite. The maximum HA yield (90.2\%) was obtained from the $0.250-0.180 \mathrm{~mm}$ size fraction of the coal sample at a reaction temperature and time of $190{ }^{\circ} \mathrm{C}$ and $7 \mathrm{~h}$. The ash content of residual coal was highest, followed by that of raw coal and HA, indicating that hydrothermal reaction can deash coal. The $\mathrm{O} / \mathrm{C}$ and $\mathrm{H} / \mathrm{C}$ ratios of HA were highest, followed by those of residual coal and raw coal, indicating an increase in the oxygen and hydrogen content of HA. Analysis of the FTIR and UV-VIS spectra showed that the macromolecular structure of the raw coal was destroyed and that the organics were degraded and hydrolyzed during the reaction process.

Author Contributions: Funding Acquisition, G.C.; Project Administration, G.C.; Writing—Review \& Editing, G.C.; Methodology, C.Z.; Formal Analysis, Z.N., X.L.; Data Curation, X.Z.

Funding: This research was funded by the China Postdoctoral Science Foundation, grant number 2016M602240; the Key Scientific and Technological Project of Henan Province, grant number 192102310462; the Henan Postdoctoral Science Foundation, grant number 172524; the Foundation for University Key Teacher by Henan Polytechnic University, grant number 2017XQG-12; the Henan Key Laboratory of Coal Green Transformation; and the Doctoral Foundation of Henan Polytechnic University, grant number B2015-13.

Acknowledgments: Thanks for the support from "China Postdoctoral Science Foundation" (Grant No. 2016M602240); "Key Scientific and Technological Project of Henan Province“" (Grant No. 192102310462); "Henan Postdoctoral Science Foundation" (Grant No. 172524); “Foundation for University Key Teacher by Henan Polytechnic University" (Grant No. 2017XQG-12); "Henan Key Laboratory of Coal Green Transformation"; and "Doctoral Foundation of Henan Polytechnic University" (Grant No. B2015-13).

Conflicts of Interest: The authors declare no conflict of interest.

\section{References}

1. Ding, Y.; Liu, M.Q.; Peng, S.M.; Li, J.H.; Liang, Y.Z.; Shi, Z.Q. Binding characteristics of heavy metals to humic acid before and after fractionation by ferrihydrite. Chemosphere 2019, in press. [CrossRef] [PubMed]

2. Qin, Z.H. New advances in coal structure model. Int. J. Min. Sci. Technol. 2018, 28, 541-559. [CrossRef]

3. Schulten, H.R.; Schnitzer, M. A state of the art structural concept for humic substances. Naturwissenschaften 1993, 80, 29-30. [CrossRef]

4. Piccolo, A. The supramolecular structure of humic substances. Soil Sci. 2001, 66, 810-832. [CrossRef]

5. Souza, F.D.; Bragança, S.R. Extraction and characterization of humic acid from coal for the application as dispersant of ceramic powders. J. Mater. Res. Technol. 2019, 7, 254-260. [CrossRef]

6. Yuan, D.W.; Xie, L.; Shi, X.W.; Yi, L.S.; Zhang, G.F.; Zhang, H.; Liu, Q.; Zeng, H.B. Selective flotation separation of molybdenite and talc by humic substances. Miner. Eng. 2018, 117, 34-41. [CrossRef] 
7. Santos, A.; Rodríguez, S.; Pardo, F.; Romero, A. Use of Fenton reagent combined with humic acids for the removal of PFOA from contaminated water. Sci. Total Environ. 2016, 563-564, 657-663. [CrossRef]

8. Yang, C.J.; Zeng, Q.R.; Yang, Y.; Xiao, R.Y.; Wang, Y.Z.; Shi, H. The synthesis of humic acids graft copolymer and its adsorption for organic pesticides. J. Ind. Eng. Chem. 2014, 20, 1133-1139. [CrossRef]

9. El-sayed, M.E.A.; Khalaf, M.M.R.; Gibson, D.; Rice, J.A. Assessment of clay mineral selectivity for adsorption of aliphatic/aromatic humic acid fraction. Chem. Geol. 2019, 511, 21-27. [CrossRef]

10. Guo, C.X.; Zhang, C.J.; Sun, Z.Y.; Zhao, X.Y.; Zhou, Q.; Hoffmann, M.R. Synergistic impact of humic acid on the photo-reductive decomposition of perfluorooctanoic acid. Chem. Eng. J. 2019, 360, 1101-1110. [CrossRef]

11. Liu, D.D.; Deng, H.; Guo, Q.S.; Ming, Q. The Application of Humic Acid in Oil Field Drilling Fluids. Humic Acid 2012, 3, 11-17.

12. Do Nascimento, F.H.; Masini, J.C. Influence of humic acid on adsorption of $\mathrm{Hg}$ (II) by vermiculite. J. Environ. Manag. 2014, 143, 1-7. [CrossRef]

13. Zhang, S.H.; Li, B.C.; Zhang, H.F.; Lin, X.F.; Liu, J.Z. Experimental study on the production of humic acids from brown coal using hydrogen peroxide. J. Anhui Agric. Sci. 2012, 40, 8677-8679.

14. Zhao, Y. Absorption of Sulfur Dioxide by Composite Absorbent Based Sodium Humate. Ph.D. Thesis, Jiao Tong University, Shanghai, China, 2014.

15. Lorencgrabowska, E.; Gryglewicz, G. Adsorption of lignite-derived humic acids on coal-based mesoporous activated carbons. J. Colloid Interf. Sci. 2005, 284, 416-423. [CrossRef] [PubMed]

16. Sun, Z.; Tang, B.; Xie, H. Treatment of waste gases by humic acid. Energy Fuel 2015, 29, 1269-1278. [CrossRef]

17. Vaz, S.; Lopes, W.T.; Martin-Neto, L. Study of molecular interactions between humic acid from Brazilian soil and the antibiotic oxytetracycline. Environ. Technol. Innov. 2015, 4, 260-267. [CrossRef]

18. Zhou, P.X. Chemical Basis of Application of Humic Acid; Chemical Industry Press: Beijing, China, 2007; ISBN 9787122010261.

19. Genuino, D.A.D.; Bataller, B.G.; Capareda, S.C.; Luna, M.D.G.D. Application of artificial neural network in the modeling and optimization of humic acid extraction from municipal solid waste biochar. J. Environ. Chem. Eng. 2017, 5, 4101-4107. [CrossRef]

20. Manzak, A.; Kurşun, C.; Yıdız, Y. Characterization of humic acid extracted from aqueous solutions with polymer inclusion membranes. J. Taiwan Inst. Chem. E 2017, 81, 14-20. [CrossRef]

21. Zhang, Y.Y.; Zong, Z.M.; Sun, Y.B.; Liu, F.J.; Li, W.T.; Wang, Y.N.; Wei, X.Y. Investigation on the structural feature of Shengli lignite. Int. J. Min. Sci. Technol. 2018, 28, 335-342. [CrossRef]

22. Zhou, F.; Cheng, J.; Liu, J.Z.; Zhou, J.H.; Cen, K.F. Improving physicochemical properties of upgraded Indonesian lignite through microwave irradiation with char adsorbent. Fuel 2018, 218, 275-281. [CrossRef]

23. Yuan, L.; Zhang, N.; Kan, J.G.; Wang, Y. The concept, model and reserve forecast of green coal resources in China. J. China Univ. Min. Technol. 2018, 47, 1-8.

24. Wang, C.P.; Xiao, Y.; Li, Q.W.; Deng, J.; Wang, K. Free radicals, apparent activation energy, and functional groups during low-temperature oxidation of Jurassic coal in Northern Shaanxi. Int. J. Min. Sci. Technol. 2018, 28, 469-475. [CrossRef]

25. Gui, X.H.; Lian, L.H.; Xing, Y.W.; Wang, B.; He, Q.Q.; Cao, Y.J. Enhancing lignite flotation performance by mechanical thermal expression treatment. Int. J. Coal Prep. Util. 2017, in press. [CrossRef]

26. Liu, F.J.; Zong, Z.M.; Gui, J.; Zhu, X.N.; Wei, X.Y.; Bai, L. Selective production and characterization of aromatic carboxylic acids from Xianfeng lignite-derived residue by mild oxidation in aqueous $\mathrm{H}_{2} \mathrm{O}_{2}$ solution. Fuel Process. Technol. 2018, 181, 91-96. [CrossRef]

27. Xia, Y.C.; Zhang, R.; Xing, Y.W.; Gui, X.H. Improving the adsorption of oily collector on the surface of low-rank coal during flotation using a cationic surfactant: An experimental and molecular dynamics simulation study. Fuel 2019, 235, 687-695. [CrossRef]

28. Doskočil, L.; Burdíková-Szewieczková, J.; Enev, V.; Kalina, L.; Wasserbauer, J. Spectral characterization and comparison of humic acids isolated from some european lignites. Fuel 2018, 213, 123-132. [CrossRef]

29. Colombo, C.; Palumbo, G.; Sellitto, V.M.; Cho, H.G.; Amalfitano, C.; Adamo, P. Stability of coprecipitated natural humic acid and ferrous iron under oxidative conditions. J. Geochem. Explor. 2015, 151, 50-56. [CrossRef]

30. Tao, J.; Han, G.H.; Zhang, Y.B.; Huang, T.F.; Li, G.H.; Guo, Y.F.; Yang, Y.B. Improving extraction yield of humic substances from lignite with anthraquinone in alkaline solution. J. Cent. South Univ. Technol. 2011, 18, $68-72$. 
31. Stefanova, M.; Gonsalvesh, L.; Marinov, S.; Czech, J.; Carleer, R.; Yperman, J. Reductive pyrolysis of Miocene-aged lignite humic acids, Bulgaria. Fuel 2016, 165, 324-330. [CrossRef]

32. Cihlář, Z.; Vojtová, L.; Conte, P.; Nasir, S.; Kučerík, J. Hydration and water holding properties of cross-linked lignite humic acids. Geoderma 2014, 230-231, 151-160. [CrossRef]

33. Drosos, M.; Jerzykiewicz, M.; Louloudi, M.; Deligiannakis, Y. Progress towards synthetic modelling of humic acid: Peering into the physicochemical polymerization mechanism. Colloid Surf. A 2011, 389, 254-265. [CrossRef]

34. Khemakhem, M.; Papadimitriou, V.; Sotiroudis, G.; Zoumpoulakis, P.; Arbez-Gindre, C.; Bouzouita, N.; Sotiroudis, T.G. Melanin and humic acid-like polymer complex from olive mill waste waters. Part I. Isolation and characterization. Food Chem. 2016, 203, 540-547. [CrossRef] [PubMed]

35. Zhang, H.Y.; Chen, G.W.; Bai, L.; Chang, N.; Wang, Y.G. Selective hydrogenation of aromatics in coal-derived liquids over novel NiW and NiMo carbide catalysts. Fuel 2019, 244, 359-365. [CrossRef]

36. Bai, L.; Karnowo Kudo, S.; Norinaga, K.; Wang, Y.G.; Hayashi, J. Kinetics and Mechanism of Steam Gasification of Char from Hydrothermally Treated Woody Biomass. Energy Fuel 2014, 28, 7133-7139. [CrossRef]

37. Li, G.Y.; Ding, J.X.; Zhang, H.; Hou, C.X.; Wang, F.; Li, Y.Y.; Liang, Y.H. ReaxFF simulations of hydrothermal treatment of lignite and its impact on chemical structures. Fuel 2015, 154, 243-251. [CrossRef]

38. Huang, Y.; Wang, Y.G.; Zhou, H.; Gao, Y.X.; Xu, D.L.; Bai, L.; Zhang, S. Effects of Water Content and Particle Size on Yield and Reactivity of Lignite Chars Derived from Pyrolysis and Gasification. Molecules 2018, 23, 2717. [CrossRef]

39. Liu, P.; Zhou, Y.; Lu, X.L.; Wang, L.L.; Pan, T.Y.; Zhang, D.X. Structural evolution of Xianfeng lignite during hydrothermal tre atment. J. Fuel Chem. Technol. 2016, 44, 129-137.

40. Liu, H.Y.; Gao, X.; Zhang, M.Y.; Zhu, Y.M.; Zhu, S.Q. Study on lignite modified by hydrothermal and the interaction be tween the oxygen containing functional groups and water. J. Fuel Chem. Technol. 2014, 42, 284-289.

41. Chang, H.Y.; Xu, W.J.; Zhang, D.X.; Gao, J.S. Study on the deoxy-modification of low rank coals under pressurized vapour conditions. Coal Convers. 2005, 28, 25-29.

42. Wang, Z.C.; Shu, H.F.; Zhang, D.X.; Gao, J.S. Effect of hydrothermal treatment on some properties of Shenhua coal. J. Fuel Chem. Technol. 2006, 34, 524-529.

43. Zhang, X.Y.; Zhen, W.J.; Sun, M.G. Green preparation process of fulvic acid from Qitai weathered coal based on hydrothermal method. Mod. Chem. Ind. 2017, 37, 116-119.

44. Swiech, W.M.; Hamerton, I.; Zeng, H.; Watson, D.J.; Mason, E.; Spencer, E.; Taylor, S.E. Water-based fractionation of a commercial humic acid. Solid-state and colloidal characterization of the solubility fractions. J. Colloid Interfaces Sci. 2017, 508, 28-38. [CrossRef]

45. Cheng, G.; Zhang, C.X.; Zhang, X.M.; Zhang, Z.L. Preparation of lignite-based activated carbon and its flue gas desulfurization performance. Mater. Res. Express 2019, 6, 025603. [CrossRef]

46. Jednak, T.; Avdalović, J.; Miletić, S.; Slavković-Beškoski, L.; Stanković, D.; Milić, J.; Ilić, M.; Beškoski, V.; Gojgić-Cvijović, G.; Vrvić, M.M. Transformation and synthesis of humic substances during bioremediation of petroleum hydrocarbons. Int. Biodeterior. Biodegrad. 2017, 122, 47-52. [CrossRef]

47. Doskočil, L.; Grasset, L.; Válková, D.; Pekař, M. Hydrogen peroxide oxidation of humic acids and lignite. Fuel 2014, 134, 406-413.

48. Wang, C.L.; Yang, X.Y.; Li, C.; Liu, C.L. The sorption interactions of humic acid onto Beishan granite. Colloid Surf. A 2015, 484, 37-46. [CrossRef]

49. Proximate Analysis of Coal; GB/T212-2008; The State Standard of the People's Republic of China; Standards Press of China: Beijing, China, 2009.

50. Guo, R.Y.; Zhang, P.; Ma, H.W. Preparation of potassium humate from brown coal of Chifeng: An experimental study. Appl. Chem. Ind. 2017, 46, 1720-1722.

51. Guo, Y.X.; Yan, K.Z.; Cui, L.; Cheng, F.Q. Improved extraction of alumina from coal gangue by surface mechanically grinding modification. Powder Technol. 2016, 302, 33-41. [CrossRef]

52. Skybová, M.; Turčániová, L'.; Čuvanová, S.; Zubrik, A.; Hredzák, S.; Hudymáčová, L'. Mechanochemical activation of humic acids in the brown coal. J. Alloy Compd. 2007, 434-435, 842-845. [CrossRef] 
53. Novotny, E.H.; Deazevedo, E.R.; Bonagamba, T.J.; Cunha, T.J.; Madari, B.E.; De, M.B.V.; Hayes, M.H. Studies of the compositions of humic acids from Amazonian dark earth soils. Environ. Sci. Technol. 2007, 41, 400-405. [CrossRef] [PubMed]

54. Yang, H.; Li, Y.S.; Zhang, Y.G. Characterization of Humic Acid Molecular Structure by Method of Infrared Spectrum and Nuclear Magnetic Resonance. Coal Convers. 2013, 36, 72-76.

55. Gong, M.; Nanda, S.; Romero, M.J.; Zhu, W.; Kozinski, J.A. Subcritical and supercritical water gasification of humic acid as amodel compound of humic substances in sewage sludge. J. Supercrit. Fluid 2017, 119, 130-138. [CrossRef]

56. Zhang, H.; Zhang, X.B.; Zhang, Y.G.; Lei, D.J. Acidic oxygen-containing groups and their inhibition methane adsorption of Yima lignite maceral components. J. China Univ. Min. Technol. 2018, 47, 1149-1156.

57. Wang, J.B.; Shi, W.F.; Tang, H.T. Spectroscopic Methods in Organic Chemistry; Peking University Press: Beijing, China, 2001; ISBN 9787301048658.

58. Qi, J.Y. The Techniques of Modern Analytical and Test; Tongji University Press: Tongji, China, 2006; ISBN 9787560831770.

59. Zheng, P. Production and Application of Humic Acid in Coal; Chemical Industry Press: Beijing, China, 1991; ISBN 7502507566.

60. Di, X.Y.; Xiao, B.H.; Dong, H.; Wang, S.J. Implication of different humic acid fractions in soils under karst rocky desertification. CATENA 2019, 174, 308-315. [CrossRef]

61. Afzal, M.Z.; Yue, R.Y.; Sun, X.F.; Song, C.; Wang, S.G. Enhanced removal of ciprofloxacin using humic acid modified hydrogel beads. J. Colloid Interfaces Sci. 2019, 543, 76-83. [CrossRef] [PubMed]

62. Yang, H.; Zhang, Y.G.; Li, Y.S.; Jiang, L.H. Molecular structural characterization of fulvic acid made by potassium fulvic acid from lignite. J. Henan Polytech. Univ. (Nat. Sci.) 2014, 33, 539-542.

63. Cheng, S.X.; Sun, S.H.; Wu, Q.H. Effect of carbonyl thiol groups on UV and visible spectra in humic acid. Jianxi Humic Acid 1982, 2, 1-8.

(C) 2019 by the authors. Licensee MDPI, Basel, Switzerland. This article is an open access article distributed under the terms and conditions of the Creative Commons Attribution (CC BY) license (http://creativecommons.org/licenses/by/4.0/). 